Case Report

\title{
"Death by a thread" - Peritonitis due to visceral perforation by a guide wire, during proximal femur osteosynthesis with DHS: A fatal case and legal implications
}

\author{
Carlos Durão ${ }^{\mathrm{a}, \mathrm{b}, *}$, André Barros ${ }^{\mathrm{b}, 1}$, Rui Guerreiro ${ }^{\mathrm{b}, 2}$, Frederico Pedrosa ${ }^{\mathrm{a}, 3}$ \\ ${ }^{a}$ National Institute of Legal Medicine and Forensic Sciences, Gabinete Medico Legal de Torres Vedras, Portugal \\ ${ }^{\mathrm{b}}$ Trauma and Orthopaedics Department, Hospital Vila Franca de Xira, Lisbon, Portugal
}

\section{A R T I C L E I N F O}

\section{Article history:}

Received 29 December 2014

Received in revised form 28 January 2015

Accepted 30 January 2015

Available online $\mathrm{xxx}$

\section{Keywords:}

Malpractice

Guide-wire migration

Neck of femur fracture

Visceral perforation iatrogenic

\begin{abstract}
A B S T R A C T
Iatrogenic intestinal perforations in orthopaedic surgery are very rare. Reports of iatrogenic lesions caused by a guide wire during femur fracture osteosynthesis are even scarcer. There are no similar reports in recent literature. As opposed to what is normally described the lesion documented in this case report was not identified on time resulting in death by peritonitis. The forensic autopsy allowed the identification of an intestinal perforation with faecal leakage to peritoneal space in association with a vesical perforation enabling the reproduction of the guide wire path. In view of the increasing number of osteosynthesis it is essential for the surgeon to be aware of possible complications due to guide wire perforations. Cases like this go unnoticed if the forensic pathologist is not familiarized with the surgical technique which may explain the rarity of such descriptions in literature.
\end{abstract}

(c) 2015 Published by Elsevier Ireland Ltd.

\section{Introduction}

Osteosynthesis of proximal femur fractures with compression plate and dynamic hip screw (DHS) or fixation with cannulated screws are among the most commonly performed osteosynthesis and often the first to be performed by the surgical residents. The DHS or cannulated screw application technique is done using a wire as a guide (guide wire) [1]. With the increasing life expectancy there are also a growing number of proximal femur fractures in the elderly population. Comorbidities are also more frequent in this age group.

\footnotetext{
* Corresponding author at: Orthopaedic Surgeon and Forensic Expert, Hospital Vila Franca Xira, Estrada Nacional n`1, Povos, 2600-009 Vila Franca de Xira, Lisboa, Portugal.

1 Address: Orthopaedics and Trauma Resident, Hospital Vila Franca Xira, Estrada Nacional $\mathrm{n}{ }^{\circ}$, Povos, 2600-009 Vila Franca de Xira, Lisboa, Portugal. Tel.: +351263006500.

${ }^{2}$ Address: Orthopaedic Surgeon, Hospital Vila Franca Xira, Estrada Nacional $\mathrm{n}^{\circ}$, Povos, 2600-009 Vila Franca de Xira, Lisboa, Portugal. Tel.: +351 263006500.

${ }^{3}$ Address: National Institute of Legal Medicine and Forensic Sciences, Gabinete Medico Legal de Torres Vedras, Portugal.
}

Abdominal pain and unspecific symptoms are frequent in the elderly who are often bedridden and sometimes unable to cooperate challenging the identification of guide wire visceral lesions $[2,3]$.

It is essential for the orthopaedic surgeon to recognize these complications which undetected can lead to death [4]. The knowledge of the surgical technique is also important to the forensic pathologist to understand the mechanism of these injuries [5].

\section{Case report}

We report a clinical case of an 80 years old patient presented with a transtrochanteric fracture after a fall. Osteosynthesis with DHS was done without any misadventure during the procedure. During the post-operative period the patient complained of abdominal discomfort with increasing intensity which was regarded as unspecific chronic pain. Two days after discharge the patient returned to the emergency department with the same complaints and was prescribed analgesics without any diagnosis been made. Four weeks later the patient returned to the emergency department with increasing pain, hydroelectrolytic imbalance and sepsis. He was admitted to the Internal Medicine department and died during the hospital stay. 


\section{Results}

Suspecting medical negligence the forensic autopsy was required. Necroscopic findings reported: operative scar with 4 inches $(10 \mathrm{~cm})$ in the right trochanteric region (Fig. 1); abdominal cavity with purulent collection with faecal matter associated with peritoneal reaction and bacterial peritonitis; abdominal adhesions with cecum perforation near the ileocecal valve (Fig. 2A and B); contiguous to this lesion there was a bladder wall haemorrhagic infiltration associated with a small single path puncture injury (Fig. 2C and D) - these findings allowed the distinction between traumatic and spontaneous intestinal perforation (Fig. 3A). Death was caused by generalized faecal peritonitis (Fig. 3B).

\section{Discussion}

Trochanteric fractures represent one fourth of all hip fractures and are the most frequent fracture in the elderly. The treatment goal is to obtain fracture stabilization to promote early return to daily activities and prevent clinical complications. These fractures are associated with high levels of morbidity and mortality. One year after fracture $20 \%$ of patients are not able to return to their normal social and familiar lives. Mortality is $10 \%$ in the first month, $27 \%$ in the first year and $15 \%$ superior when comparing to the same age group without fracture $[2,3,6]$. Common severe complications are deep venous thrombosis, pneumonia, urinary tract infection and myocardial infarction [2,3]. The trauma associated with a fall, the fracture and the surgical intervention can frequently increase the frailty of an already sick patient as often elders are.

The most frequent DHS associated complications are the osteosynthesis failure by lost or inadequate fracture reduction, sliding screw cut out or its migration to pelvic space, non-union and infection - as with all surgical techniques these depend on the surgeon's expertize, the procedure learning curve and patient and fracture characteristics [6,7].

Technically sliding screw placement is done through the introduction of a guide wire from de femoral neck to the subchondral bone in the femoral head or the acetabulum. This process is controlled by intraoperative fluoroscopy. Material failure, a bent guide wire adherent to the drill or bony fragments inside the drill can cause wire migration [7-11]. In the past the excessive introduction of the guide wire was a common complication but nowadays with the widespread use of image intensifier in the operating room this is no longer frequent or acceptable.

Feeney et al. demonstrated in cadaveric studies the occurrence of intra-abdominal lesions during the placement of three guide wires in a triangular shape as used in femoral neck fracture
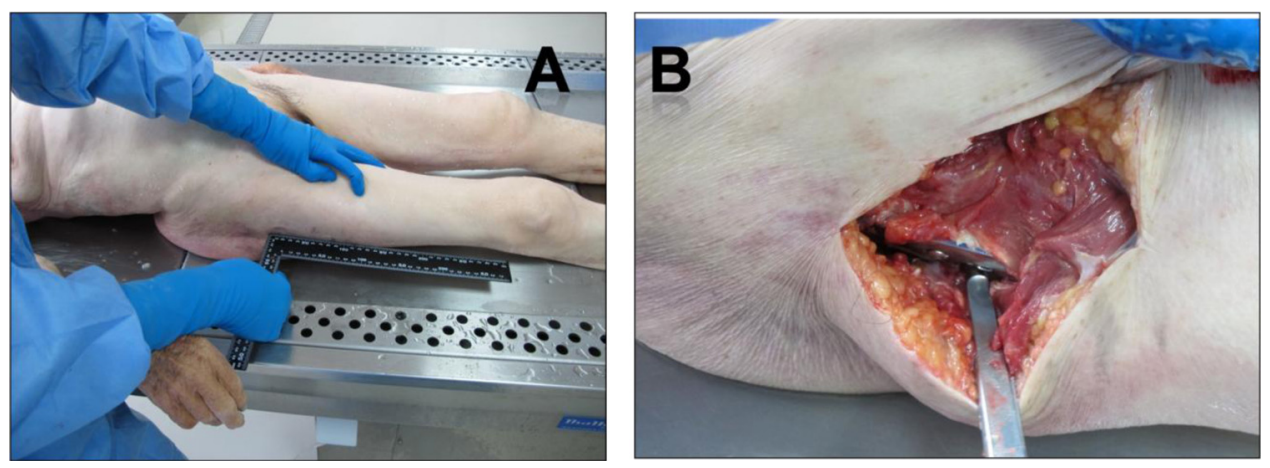

Fig. 1. Macroscopic examination: surgical wound (A); DHS in the right femur (B).
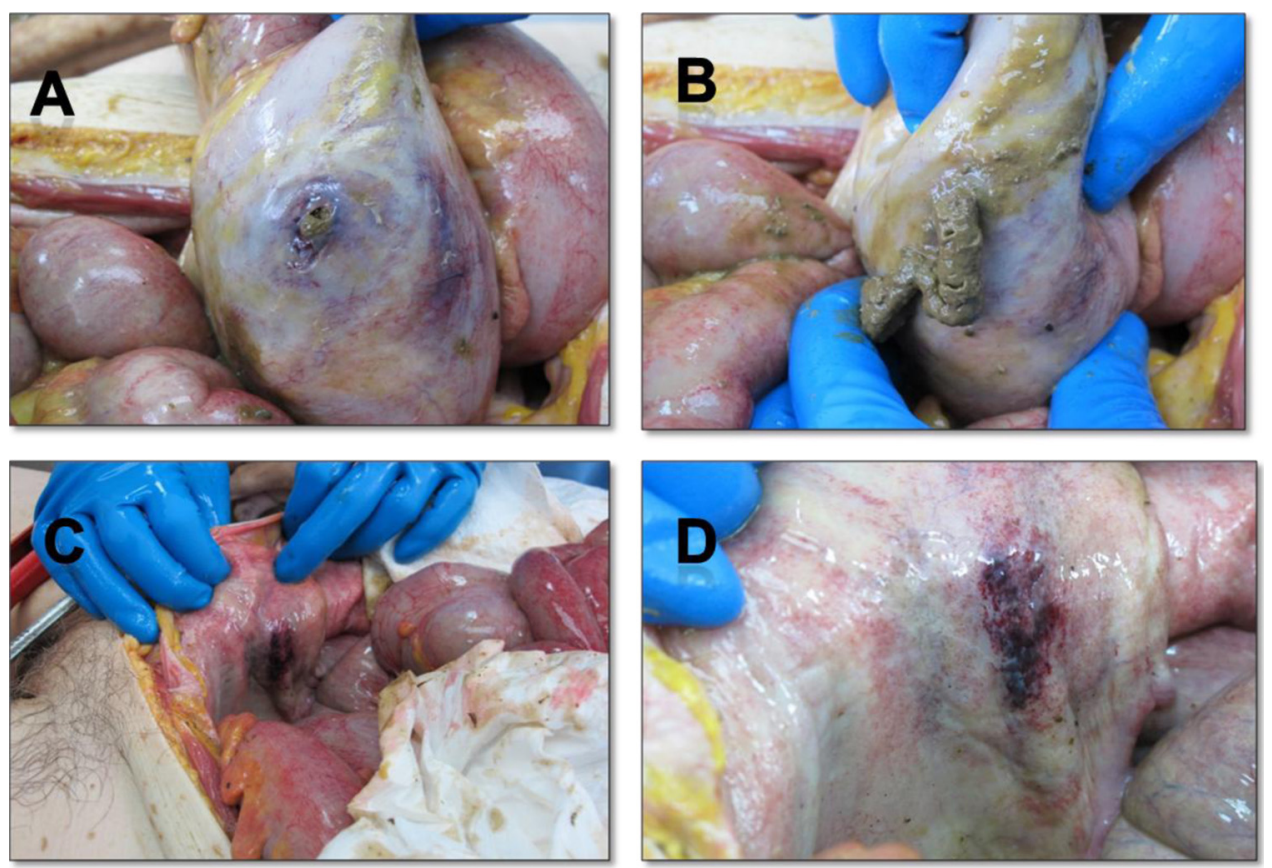

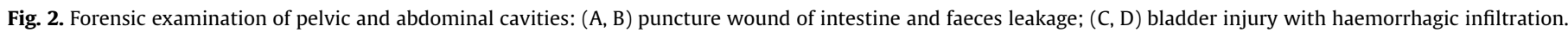

Please cite this article in press as: C. Durão, et al., "Death by a thread" - Peritonitis due to visceral perforation by a guide wire, during proximal femur osteosynthesis with DHS: A fatal case and legal implications, Forensic Sci. Int. (2015), http://dx.doi.org/10.1016/ j.forsciint.2015.01.040 

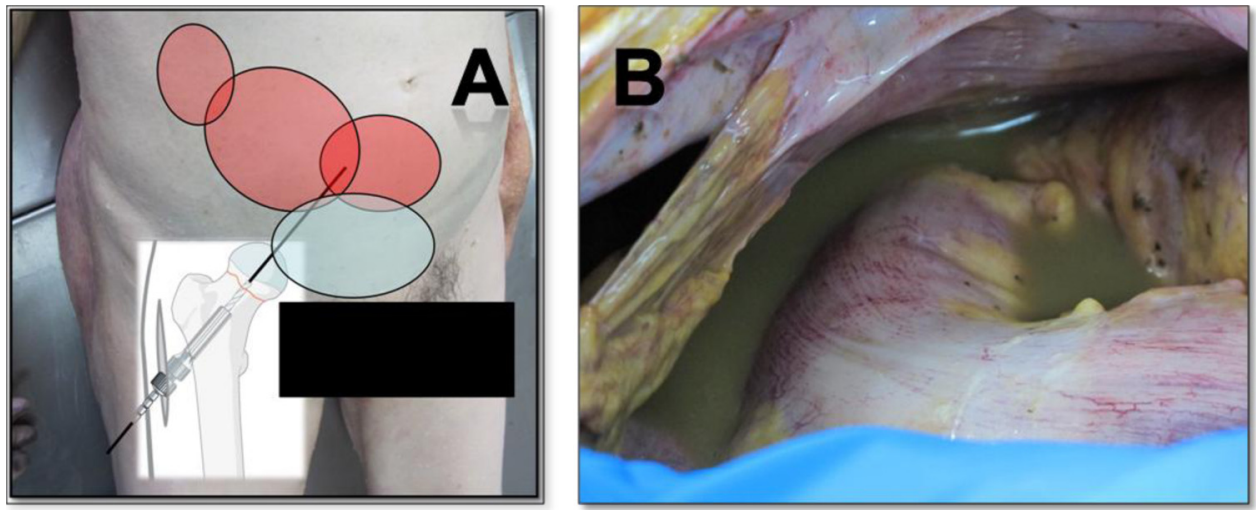

Fig. 3. Injury dynamic reconstitution: viscous and vesical puncture wound by guide wire (A). Faecal peritonitis (B).

treatment. In 10 cadaveric models studied by the introduction of 60 guide wires, 12 cases of rectum lesions, 8 cases of external iliac artery perforations, 5 sigmoid lesions, 4 bladder injuries, 2 small intestine lesions and one ureter lesion where documented [12]. However a correlation between the distance covered by the guide wire and the injury sustained was not established. Noticeably just as little as $4 \mathrm{~mm}$ of intra-pelvic penetration by the guide wire can cause injury to the obturator nerve and if a penetration is over $20 \mathrm{~mm}$ a sigmoid injury can occur [13]. Bizarre guide wire migrations have been reported [14-16]. Vascular injuries are reported and can be fatal in the post-operative period. A vesical catheter is recommended pre-operatively as the risk of injury to an empty bladder is inferior [13].

\section{Conclusion}

All surgical techniques have associated risks. Hollow viscera perforation is possible, even in a procedure as simple as a DHS or cannulated screw placement. The careful observation of every surgical step is essential. Mishra et al. proposed some guiding steps to avoid these complications: inspection of the lumen of all drills, avoidance of abusive guide wire reutilization, the use of cannulated instruments and always use fluoroscopic image control. Every complication should be documented in the clinical report $[10,13,17]$. Post-operative abdominal pain after hip, pelvic or spinal surgery should be carefully analyzed.

\section{References}

[1] Inadvertent Advancement of Wires with Trauma/Orthopaedic Guidewire Cannulated Systems, Medical Devices Agency safety notice, 2001, p. 14.
[2] H. Kesmezacar, E. Ayhan, M.C. Unlu, A. Seker, S. Karaca, Predictors of mortality in elderly patients with an intertrochanteric or a femoral neck fracture, J. Trauma 68 (January (1)) (2010) 153-158.

[3] P. Haentjens, J. Magaziner, C.S. Colón-Emeric, D. Vanderschueren, K. Milisen, B. Velkeniers, S. Boonen, Meta-analysis: excess mortality after hip fracture among older women and men, Ann. Intern. Med. 152 (March 16 (6)) (2010) 380-390.

[4] T.M. Gedebon, R.A. Wong, W.D. Rappaport, P. Jaffe, D. Kahsai, G.C. Hunter, Clinical presentation and management of iatrogenic colon perforations, Am. J. Surg. 172 (5) (1996) 454-457

[5] F.P. Busardò, P. Frati, I. Carbone, P. Pugnetti, V. Fineschi, Iatrogenic left common iliac artery and vein perforation during lumbar discectomy: a fatal case, Forensic Sci. Int. (January) (2015).

[6] S.T. Tsang, S.A. Aitken, S.K. Golay, R.K. Silverwood, L.C. Biant, When does hip fracture surgery fail? Injury 45 (July (7)) (2014) 1059-1065.

[7] M. Hrubina, M. Skoták, J. Běhounek, Complications of dynamic hip screw treatment for proximal femoral fractures, Acta Chir. Orthop. Traumatol. Cech. 77 (October (5)) (2010) 395-401.

[8] P. Mishra, V.K. Gautam, Broken guide wire with intrapelvic protrusion: a technique for removal, Injury 35 (2004) 1324-1326.

[9] V. Johri, V. Gupta, Orthopaedic guide wire injury to ileum in a case of fracture neck of femur, Indian J. Surg. 75 (June (Suppl. 1)) (2013) S36-S37.

[10] P. Mishra, P. Jain, A. Aggarwal, A. Upadhyay, M. Lalit, V.K. Gautam, Intrapelvic protrusion of guide wire during fixation of fracture neck of femur, Injury 33 (2002) 839-841.

[11] S. Kottmeier, C.T. Born, H. Saul, Laparoscopic retrieval of a migrating intrapelvic pin: case report and review of literature, J. Trauma (1993).

[12] M. Feeney, E. Masterson, P. Keogh, W. Quinlan, Risk of pelvic injury from femoral neck guidewires, Arch. Orthop. Trauma Surg. 116 (1997) 227-228.

[13] F. Anderson, S. Diogo Ranier de Macedo, et al., Abdominal injuries due to use of guide wire in hip surgery experiments. Cadaveric study, Acta Ortop. Bras. 18 (2) (2010) 75-78.

[14] F.A. Lyons, C.A. Rockwood, Migration of pins used in operations on the shoulder, J. Bone Joint Surg. 72A (8) (1990) 1262-1267.

[15] R.L. Clark, J.W. Milgram, D.H. Yawn, Fatal aortic perforation and cardiac tamponade due to a kirschner wire migrating from the right sternoclavicular joint, Southern Med. J. (1974).

[16] F. Potter, A.J. Fiorini, J. Knox, P.B. Rajesh, The migration of kirschner wire from shoulder to spleen: brief report, J. Bone Joint Surg. (1988).

[17] C. Natali, P. Ingle, J. Dowell, Orthopaedic bone drills: can they be improved? J. Bone Joint Surg. (1996) 78B. 